\title{
Introduction
}

\section{Satoshi Inomata}

The characteristic feature of the recent global economic crisis is the speed and extent of the shock transmission. The rapid development of crossnational production networks over the past several decades has significantly deepened the economic interdependency between countries, and a shock that occurs in one region, whether positive or negative in nature, will be swiftly and widely transmitted to the rest of the globe. The sudden contraction of world trade and output was, indeed, a negative outcome of this intertwined global economic system.

The major focus of this book is directed at the analysis of 'triangular trade through China', which is considered to have formed the principal mechanism of shock transmission in the Asia-Pacific region under the crisis.

The USA, one of the main players of the 'triangular trade', has always been the largest customer for the products of the region. Its consumption demand, backed by enormous purchasing power, was a leading catalyst for regional output growth.

In the first decade of the twenty-first century, China became a major trade partner for the United States, and rapidly increased its exports of final consumption goods to US markets to meet their unlimited consumption demand. Here, China specialized in the final assembling stage of the production process, since its technical requirement is quite labourintensive and hence advantageous for a country with a massive labour force.

The growth of China's manufacturing export is supported by the supply of intermediate inputs from other Asian countries. In contrast to China, other emerging economies in the region specialized in the production of parts and accessories, which usually require higher levels of technology and sophisticated management skills.

Therefore, the 'triangular trade through China' assumes a structure of product flows whereby: (1) Asian countries (including Japan) produce parts and accessories and export them to China; and (2) China assembles them into final goods; (3) which are further exported to the US markets for consumption (see Figure I.1). 


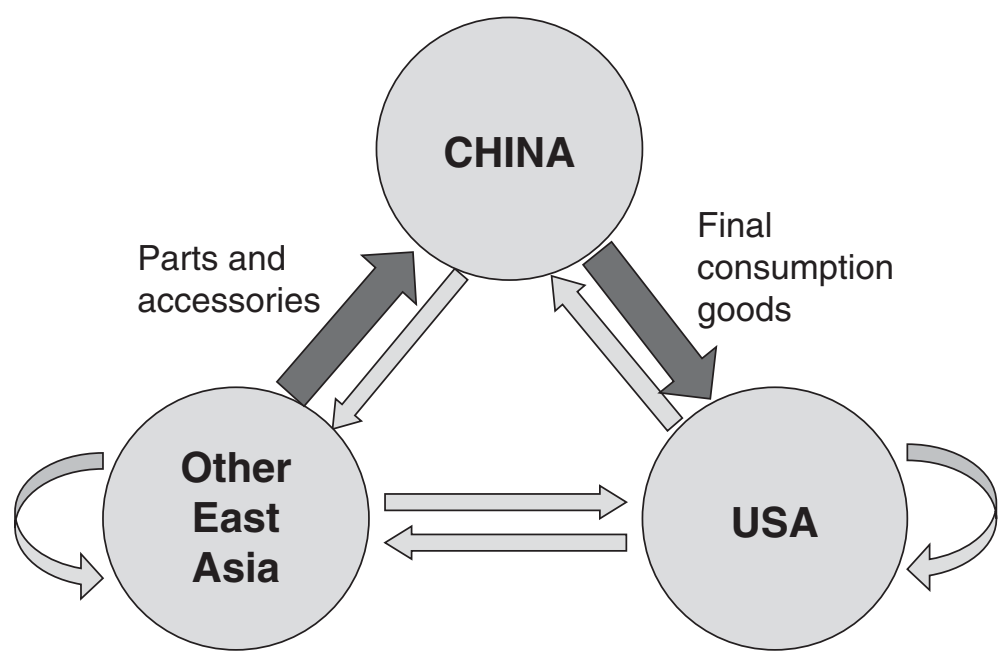

Source: Drawn by the author.

\section{Figure I.1 Triangular trade through China}

There is no doubt that the 'triangular trade through China' prevailed as a primary growth engine for the Asia-Pacific region. The opposite picture, however, is equally possible and valid. The collapse of US consumption demand under the crisis caused a significant decline of Chinese exports to the United States, which further reduced China's import demand for intermediate inputs from neighbouring Asian countries. The negative shock of the economic crisis propagated quickly and extensively throughout the region via complex production networks among countries, yet, on top of this, the 'triangular trade through China' is considered to have functioned as the US-Asia 'turnpike' for the shock transmission within the region.

The direct impact of the contraction of the US import demand can be measured by a simple reference to the change in trade statistics, but the entire effect of the impact on industries, both through direct and indirect channels, can be examined only by probing the intertwined production networks among the countries (see Figure I.2). The Asian International Input-Output Tables (AIO tables), constructed by the Institute of Developing Economies, JETRO, are used for this particular purpose, and they enable us to capture all recursive impacts of negative demand shock, both direct and indirect, on every industry of every country in the AsiaPacific region. ${ }^{1}$ 


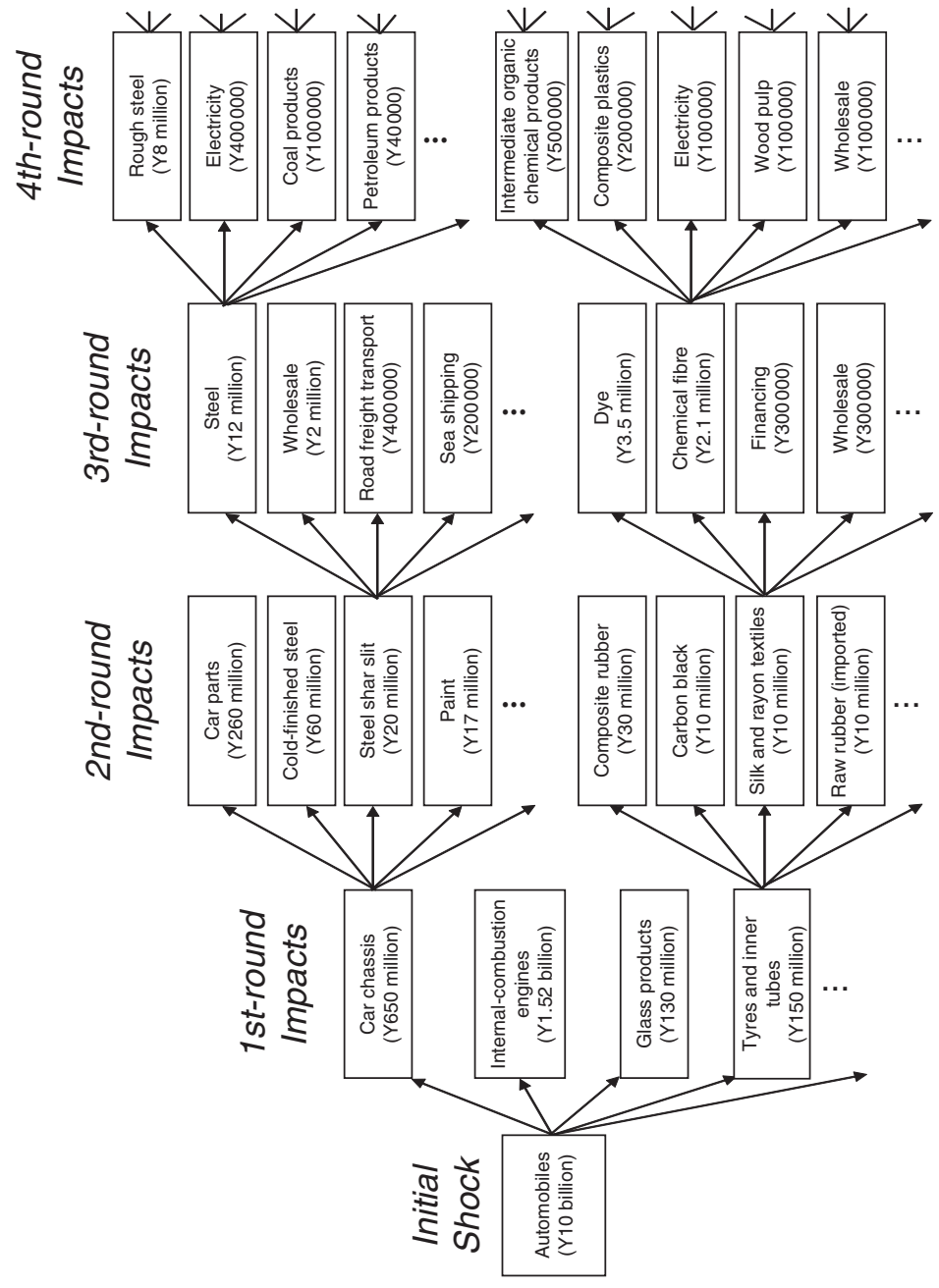

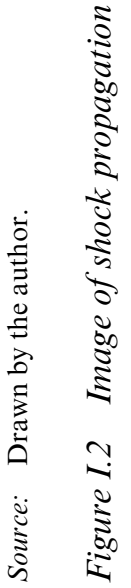




\section{CHAPTER 1: THE TRIANGULAR TRADE: THE SHOCK TRANSMISSION MECHANISM IN THE ASIA-PACIFIC REGION}

Chapter 1 attempts to measure the impact of the crisis by a simple multiplier analysis using an orthodox international input-output model. A change or 'shock' that occurs in one industry in one country will be transmitted and amplified through complex cross-national production networks, and inflict a larger and wider impact on the rest of the region. This is called a multiplier effect. By decomposing the multiplier effect into three types according to the shock transmission channels (the domestic linkage channel, the 'triangular trade' channel, and other inter-country linkage channel), the chapter reveals that the shock delivered by the 'triangular trade through China' caused significant damage to the entire Asia-Pacific region.

For the analysis at the industrial level, it emerges that the output of manufacturing products with complex architecture, such as computer equipment and electrical appliances, was seriously affected by external shocks. The production of these goods is more prone to offshoring since its manufacturing process is separable into several stages and the parts and accessories are relatively compact and lightweight (and can hence be easily delivered across countries). Consequently, the production activities of these goods, extensively connected to regional production networks, became highly vulnerable to shocks coming from outside.

\section{CHAPTER 2: IMPACT OF THE GLOBAL ECONOMIC CRISIS ON EMPLOYMENT IN THE ASIA-PACIFIC REGION}

Chapter 2 continues the analytical focus of Chapter 1, yet shifts its attention to employment issues. It devises the indices of 'employment gain potential' and 'employment give-out potential', which present a balance sheet of employment opportunities for each country brought about by the engagement in international trade. The combination of both indices shows that, in the Asia-Pacific region, China is the biggest receiver of job opportunities, while the USA is the most benevolent provider. From 2000 to 2008, however, there was a marked structural change in the gain/ give-out relationship of the region. China continues to benefit from the USA's strong demand for its exports, yet started to give out job opportunities to other neighbouring countries through the increase in its import demand for intermediate goods from the same. Here, the emergence of 
'triangular trade through China' is observed again. What happened in the commodity markets was echoed in the labour markets in the AsiaPacific region.

Chapter 2 also contributes to the analysis by calculating the impact of the crisis on regional employment. By using the same analytical framework as in Chapter 1 but extending the model of 'employment multipliers', the chapter simulates the potential number of job losses in each country for the years 2008 and 2009. A particular focus is placed on the 'transfer of unemployment' between countries, in which China is found to be the main transmission hub for Asian countries.

\section{CHAPTER 3: INTERNATIONAL TRADE AND REAL TRANSMISSION CHANNELS OF FINANCIAL SHOCKS IN GLOBAL PRODUCTION NETWORKS: AN ASIAN-USA PERSPECTIVE}

The analyses in the first two chapters are based on the demand-driven model, generally known as the 'Leontief model'. The contraction of final demand leads to a decline in the output of final goods, which reduces the demand for and thus the production of parts and accessories, which further induces the output decline of sub-parts and materials, and so on. The negative impact is transmitted 'backward' along production chains from downstream to upstream industries.

The impact can also propagate in the opposite direction. The change that occurs at a certain point in the vertical chain is recurrently transferred to the subsequent stages of the production process, moving 'forward' all the way down to the terminals of supply-demand circuits. The analytical model used to capture such transmission mechanism is of the supplydriven type, known as the 'Ghosh model', which forms a dual counterpart of the Leontief model.

Unlike the other studies conducted in this book, Chapter 3 deals uniquely with the price effect of the financial crisis by employing the supply-driven model. Its analytical focus is devoted to the impact of the credit crunch, the global conjuncture of the current state, which is anticipated to disrupt the smooth functioning of vertical production networks.

After the sub-prime shock, many small-scale manufacturers are finding it increasingly difficult to gain access to credit markets, and at some point may choose to shut down factories lacking operational finance. The sudden stop in the supply of key intermediate products will force downstream clients to seek other sources, yet switching from one supplier to another is a difficult task for the producers of differentiated products, 
especially of high-tech industries, which use highly knowledge-intensive parts and components and require specific production technologies. Finding an appropriate alternative involves considerable costs (searching costs, transaction costs, training costs and so on). Consequently, the unit cost of production is bound to increase. The increase in production cost is a typical example of supply-side shocks, which will reverberate and propagate to other industries by cumulative price mark-ups along the vertical production chains.

Applying the supply-driven model to the AIO tables, the chapter simulates the mark-up effect of a price shock for the selected Asian countries in the face of the contagious credit crunch. By doing so, it attempts to bridge the real and monetary sides of the economies under the crisis.

The simulation results show that the relative size of the shock on the domestic economy depends on its degree of openness, and also on the relative size of the originating industrial sector in relation to the rest of the economy. As for the cross-national transmission of price shocks, Japan is found to be the largest exporter of potential inflation, while Malaysia and Thailand are the most vulnerable to such shocks, apparently due to the considerable foreign orientation of the manufacturing sector. From 2000 to 2008, China increased its influence as an exporter of the price shock, yet its vulnerability to imported shocks remained relatively stable.

\section{CHAPTER 4: VERTICAL SPECIALIZATION AT THE TIME OF ECONOMIC CRISIS}

The last few decades have been marked by the rapid development of vertical production networks within the Asia-Pacific region. Manufacturing goods are no longer produced in a single country. Production processes are fragmented into several stages, and countries specialize in each production stage according to their own comparative advantages.

Chapter 4 is devoted to investigating the impact of the crisis on the vertical production networks of the Asia-Pacific region, by adopting the Vertical Specialization (VS) index. The VS index measures a country's degree of participation in cross-national production networks by calculating the amount of 'imported inputs used for producing a good that is subsequently exported'. The chapter, however, extends the model by employing the AIO tables as principal data, the unique feature of which enables the VS index to be decomposed into two indices: 'VS_i' and 'VS_f'.

VS_i is the VS index of exports for intermediate usage in foreign countries, which shows the level of participation in the production of parts and components. VS_f, on the other hand, is the VS index of exports for 
overseas final consumption, which is thus considered to indicate the degree of engagement in the final assembly process.

From the viewpoint of vertical production chains, whether a country is mainly exporting intermediate goods or final consumption goods is directly related to the country's technological profile within the international division of labour. It is generally considered that the production of parts and components requires sophisticated technology with qualified logistics management for just-in-time delivery. The assembly of components required to complete the final consumption goods, in contrast, entails relatively simple routines with low working skills. So, by comparing the values of VS_i and VS_f, one can profile the technological development of the countries concerned.

The calculation results show that the upstream production process of intermediate goods (as measured by the VS_i index) was relatively 'resistant' to the impact of the crisis, compared to the assembly process at the end of the production chains (as measured by the VS_f index), which was directly and immediately affected by the contraction of final demand.

The analysis also confirms the prevalence of the 'triangular trade through China', yet with a striking new finding. The 'triangular trade' presumed China's role to be a mere assembler of final products. The comparison of VS_i and VS_f indices of China, however, reveals that the country has already 'stepped up' the technological ladder and recently promoted its position within the regional production networks from a simple assembler of final goods to a producer of parts and components. The "triangular trade through China' has undergone a significant qualitative change in recent years, and its contents are no longer the same as a decade ago.

\section{CHAPTER 5: THE IMPACT OF THE FINANCIAL CRISIS ON FACTORY ASIA}

Now, based on the VS analysis of Chapter 4, the importance of production networks for intermediate goods is very apparent. They determine the length of the vertical production chains and the complexity of supplydemand networks. In order to envisage the post-crisis production system in the Asia-Pacific region, there is a need for detailed analysis of the trade mechanism of intermediate goods.

Chapter 5 contributes to this subject. This chapter employs a conventional regression analysis with the Ordinary Least Squares method, in order to identify the determinants of trade in intermediate products. The design of the equation system is based on the popular gravity model, yet the originality and strength of the study resides in its treatment of datasets. 
Usually, it is quite difficult to obtain consistent time series data for intermediate goods trade. The UN trade statistics, for example, are often criticized in that the definition of intermediate products is rather arbitrary and goods are categorized in an ad hoc fashion. The research of this chapter instead focuses on the unique features of the AIO tables. These tables offer a complete and harmonized set of panel data for the trade of intermediate goods in four dimensions: the country of origin, the country of destination, the industrial sector, and the reference year. The regression model of the study is constructed in such a way as to optimally exploit these international $\mathrm{I}-\mathrm{O}$ table properties.

Another characteristic of the study is that it includes the financial aspect of international trade in the model. It refers to the data provided by Institutional Investor, upon which the credibility of the financial markets of each country concerned is constructed as an explanatory variable. This is a very strong and important formulation for our research since the financial meltdown in the United States was the main trigger of the crisis.

Empirical results show that the regional production networks of Asia, or 'Factory Asia', have begun to develop without relying on external forces such as the US consumption demand. Its robust production system, backed by the sound operation of financial markets, is expected to enhance regional self-sufficiency and improve its resistance to external shocks. The finding is along the lines of support for the prediction of the VS analysis in Chapter 4, which suggests the possible re-organization of the 'triangular trade' structure that has dominated the Asia-Pacific region throughout the last decade.

\section{CHAPTER 6: TO WHAT EXTENT WILL THE SHOCK BE ALLEVIATED? THE EVALUATION OF CHINA'S COUNTER-CRISIS FISCAL EXPANSION}

So, what will be the key element of the post-crisis 'Factory Asia'? No one can deny the importance of China in bringing Asia back on track. Chapter 6 considers the potential of the Chinese economy for regional economic growth, by evaluating the effect of China's counter-crisis fiscal measures, which were recently implemented on an unprecedented scale.

The chapter adopts an orthodox I-O model of impact multipliers for its study, yet the data used for the analysis is especially unique. It is the Transnational Interregional Input-Output Table between China and Japan, the newest product of the Institute of Developing Economies. In this dataset the inter-regional $\mathrm{I}-\mathrm{O}$ tables of both China and Japan are harmonized and interlinked in a single matrix, so that the cross-national 
transmission of impact from one sub-region in China, say Huanan, to one sub-region in Japan, say, Hokkaido, can be consistently measured. Feeding the data into the analysis enables us to see the 'intra'-regional multiplier effect and 'inter'-regional multiplier effect individually, and thus we are able to probe the detailed, region-to-region linkage structure from a geographical perspective.

The empirical results indicate that the production of export-driven districts such as Huadong and Huanan significantly declined during the crisis, and induced drops in output, not only in neighbouring Huazhong and Huabei, but also further in other Asian economies such as Japan, South Korea, Taiwan and ASEAN countries.

The recent fiscal measure adopted by the Chinese government, however, is expected to turn the situation around. The study reveals that the policy mainly functions to stimulate the economies of inland regions such as Xinan and Huazhong, although Huabei and Huadong in coastal areas may also benefit through inter-regional economic linkages. Moreover, the impact of fiscal expansion transcends international borders and reaches other Asian countries through extensive trade channels in the Asia-Pacific region.

\section{CHAPTER 7: AN INPUT-OUTPUT ANALYSIS OF POST-CRISIS REBALANCING IN THE ASIA-PACIFIC ECONOMY}

The increasing influence of China and other emerging economies in determining the global distribution of wealth, as seen in the preceding chapters of the book, has brought wide attention to the issues of rebalancing the world economy. Chapter 7 completes our research by considering the post-crisis rebalancing of expenditures among and within surplus and deficit countries as a key policy priority.

The chapter examines the implications of rebalancing expenditure categories in ten Asia-Pacific countries for the structure of production. An aggressive rebalancing scenario (based on 2007 current account data) is constructed, and its detailed production implications are analysed using the inter-country $\mathrm{I}-\mathrm{O}$ framework.

The analysis reveals that changes associated with eliminating excessive international imbalances are modest relative to major expenditure categories in the Asia-Pacific region. Moreover, significant overlaps in the production induced by different types of expenditures dampen the output effects of shifts among them.

This does not mean that rebalancing will be easy - spending reallocations 
are politically difficult - but the need to 'reinvent' Asia's growth model appears to be overstated. Policy makers should be well comforted by the result of analysis that expenditure adjustments required for rebalancing are attainable without involving serious dislocations in industrial structure or patterns of economic growth.

The book was written to serve both the interests of non-specialists and I-O experts alike, and assumes no preliminary knowledge about international input-output analyses. Readers, however, may like to glance at the 'Explanatory notes' in Chapter 8 before proceeding to the main chapters, which might help deepen understanding of the basic logic behind the arguments.

\section{NOTE}

1. Traditionally, the input-output model of impact analysis has been used to measure the effect of positive shock, such as that of the special procurement from the Olympic Games or World Expo. The analysis of positive shock, however, is subject to two practical difficulties. Firstly, shock propagation is bound to stop when the repercussion of extra demand hits the production bottleneck of industries. Secondly, manufacturers may try to meet the extra demand by running down their stocks rather than increasing output, in which case the shock propagation will also come to a halt.

As for negative shock, in contrast, the transmission of impact does not presume this kind of 'obstacle'. While manufacturers may not be able to produce more due to their production capacity limits, they can always choose to produce less. Also, because retaining stock incurs cost, manufacturers usually opt to reduce production when they face a declining demand for their products, rather than maintaining the same production level and piling up undesired inventory.

Therefore, the impact analysis seems to be more suitable for analysing negative shock than positive shock. 